\title{
Fonksiyonel Derecelenmiş Malzemeli Kirişlerin Sönümlü ve Sönümsüz Zorlanmış Titreşim Analizi
}

\author{
Timuçin Alp ASLAN ${ }^{* 1}$, Ahmad Reshad NOORI ${ }^{2}$, Beytullah TEMEL ${ }^{1}$ \\ ${ }^{1}$ Çukurova Üniversitesi, Mühendislik Fakültesi, İnşaat Mühendisliği Bölümü, Adana

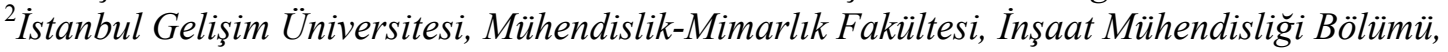 \\ Istanbul
}

Geliş tarihi: $27.05 .2020 \quad$ Kabul tarihi: 30.07 .2020

$\ddot{O} z$

$\mathrm{Bu}$ çalışmada, kesit yüksekliği boyunca fonksiyonel olarak derecelendirilmiş (FD) malzemeli kirişlerin çeşitli dinamik yükler altında zorlanmış titreşim davranışı üzerine bir araştırma yapılmıştır. Farklı sınır koşulları, uzunluk-yükseklik $(L / h)$ oranları ve malzeme değişim katsayılarının Euler-Bernoulli ve Timoshenko kirişlerinin sönümlü ve sönümsüz zorlanmış titreşimleri üzerindeki etkileri de parametrik olarak incelenmiştir. FD malzemeli çubukların davranışını idare eden hareket denklemleri, minimum toplam enerji prensibi yardımıyla elde edilmiştir. Elde edilen kanonik diferansiyel denklemler, Tamamlayıcı Fonksiyonlar Yöntemi (TFY) yardımıyla Laplace uzayında sayısal olarak çözülmüştür. Viskoelastik malzeme durumunda Kelvin tipi sönüm modeli kullanmıştır. Bu modelde elastik sabitler, elastik-viskoelastik analoji ile Laplace uzayındaki kompleks karşıtları ile değiştirilir. Önerilen yöntemin sonuçlarının doğruluğu, ANSYS sonlu elemanlar paket programının sonuçları ile karşılaştırılarak kanıtlanmıştır.

Anahtar kelimeler: Fonksiyonel derecelenmiş malzeme; Tamamlayıcı fonksiyonlar yöntemi, Ters Laplace dönüşümü, Kelvin sönüm modeli

\section{Damped and Undamped Forced Vibration Analysis of Beams Made of Functionally Graded Materials}

\begin{abstract}
In this study, a research has been conducted on the forced vibration behavior of beams with functionally graded (FG) material along the height of the cross-section under various dynamic loads. The effects of different boundary conditions, length-height $(L / h)$ ratios and material variation coefficients on damped and undamped forced vibrations of Euler-Bernoulli and Timoshenko beams are also examined parametrically. The equations of motion which govern the behavior of the beams with FG material have been obtained with the help of the minimum total energy principle. The canonical differential equations
\end{abstract}

*Sorumlu (Corresponding author) yazar: Timuçin Alp ASLAN, taslan@cu.edu.tr 
obtained are solved numerically in the Laplace space with the aid of Complementary Functions Method (CFM). Kelvin type damping model is used in case of viscoelastic material. In this model, elastic constants are replaced by their complex counterparts in the Laplace space by means of the elasticviscoelastic analogy. The accuracy of the results of the proposed method has been confirmed by comparing it with the results of the ANSYS finite element package program.

Keywords: Functionally graded materials, Complementary functions method, Inverse Laplace transform, Kelvin damping model

\section{GíRiş}

FD malzemeler, mekanik özellikleri bir noktadan diğer bir noktaya sürekli olarak değişen malzemelerdir. Farklı malzemelerin üstün özellikleri bir araya getirilerek oluşturulan FD kirişler, modern mühendislik uygulamalarında yaygın olarak kullanılmaktadır. Bu sebeple FD kirişlerin çeşitli yüklemeler altında davranışı önem kazanmış ve bu konu üzerine birçok araştırma yapılmıştır.

Qian ve Ching [1], galerkin yöntemini kullanarak FD ankastre mesnetli kirişin dinamik analizini incelemişlerdir. Aydoğdu [2], basit mesnetli kalınlık boyunca FD kirişin serbest titreşimini çeşitli yüksek mertebe ve klasik kiriş teorilerini kullanarak araştırmıştır. Hamilton prensibini kullanarak hareket denklemlerini elde edip, Navier yöntemi yardımıyla kirişin doğal titreşim frekanslarını bulmuştur. Li [3], FD kirişlerin dinamik davranışlarını araştırmak için yeni bir birleşik yaklaşım yöntemi ortaya koymuştur. Teorisinde, dördüncü dereceden kısmi diferansiyel denklemi türeterek problemin fiziksel niceliklerini bu denklemin çözümü yardımıyla elde etmiştir. Kirişin frekans denklemini belirleyerek serbest titreșim analizini yapmıştır. Sina ve arkadaşları [4], FD kirişlerin serbest titreşim frekanslarını hesaplamışlardır. Yanal normal gerilmelerin sıfır olduğu varsayımına dayanarak Hamilton prensibi yardımıyla hareket denklemlerini elde etmişlerdir. Analitik yöntemi kullanarak buldukları değerler ile farklı kiriş teorileri kullanılarak elde edilen sonuçları karşılaş̧ırmışlardır. Civalek ve Kiracıoğlu [5], Timoshenko kirişinin serbest titreşim frekansını ayrık tekil konvolüsyon yöntemiyle hesaplamışlardır. Alshorbagy ve arkadaşları [6], FD kirişin serbest titreşim analizini sonlu elemanlar yöntemini kullanarak araştırmışlardır. Çeşitli sınır şartlarının, malzeme dağılımlarının ve kalınlık oranlarının kirişin dinamik karakteristiği üzerindeki etkilerini incelemişlerdir. Atmane ve arkadaşları [7], değişken kalınlıklı FD kirişlerin serbest titreşim analizini yapmışlardır. Malzeme için eksponansiyel değişim kabulü yapmışlardır. Anandrao ve arkadaşları [8], çalışmalarında EulerBernoulli kiriş teorisi ve Timoshenko kiriş teorisine dayanan iki ayrı sonlu eleman formülasyonu geliştirerek kirişlerin serbest titreşim frekanslarını bulmuşlardır. Sonlu elemanlar yönteminin denklem sistemini elde etmek için virtüel iş prensibini kullanmışlardır. Pradhan ve Chakraverty [9], kalınlık boyunca malzeme özellikleri değişen, farklı sınır şartlarına sahip FD kirişlerin serbest titreşim analizlerini, klasik ve birinci mertebeden kayma deformasyon kiriş teorilerine dayandırarak incelemişlerdir. Kiriş kesitlerinin yer değiştirme bileşenlerini gösteren deneme fonksiyonlarını, hesaplama kolaylığı için temel sınır koşullarını sağlayacak şekilde basit cebirsel polinom formlarında ifade etmişlerdir. Rayleigh-Ritz metodunu kullanarak temel denklemleri elde etmişlerdir. Demir ve Öz [10], viskoelastik sınır koşulları altında FD bir kirişin boyutsuz titreşim frekans parametrelerini sonlu elemanlar yöntemini kullanarak hesaplamışlardır. Su ve Banerjee [11], kalınlık boyunca FD kirişlerin serbest titreşim frekanslarını dinamik rijitlik matrisini geliştirerek araştırmışlardır. Çalışmalarında, Wittrick-Williams algoritmasını çözüm tekniği olarak kullanmışlardır. Jing ve arkadaşları [12], düzgün yayılı yük etkisi altında FD kirişlerin titreşim analizi için merkezi sonlu hacim yöntemi ve Timoshenko kiriş teorisi 
kombinasyonuna dayanan yeni bir yaklaşım geliştirmişlerdir. Analizlerinde farklı kayma düzeltme faktörlerinin etkisini incelemişlerdir. Avcar ve Alwan [13], Rayleigh kiriş teorisine göre türetilen denklemleri kullanarak FD kirişin serbest titreşim analizini yapmışlardır. Lee ve Lee [14], Euler-Bernoulli kirişlerinin serbest titreşim davranışlarını transfer matris metoduyla incelemişlerdir. Kirişin iki ucunda, sınır şartları arasında bir ilişkki kurarak FD malzemeli kiriş için kesin transfer matrisini elde etmişlerdir. Turan ve Kahya [15], çalışmalarında, FD Timoshenko kirişlerin doğal frekanslarını Navier tipi çözüm yöntemini kullanarak elde etmişlerdir. Akbaş [16], FD konsol kirişin serbest titreşim davranışını ortotropik malzeme modeli kullanarak incelemiştir. Kalınlık boyunca FD kirişin titreşim analizi için düzlem parçalı sürekli ortam modeli ve sonlu elemanlar yöntemini kullanmıştır. Nam ve arkadaşları [17], birinci mertebe kayma deformasyon teorisine ve interpolasyon polinomlarına dayalı formülasyonların çözümü ile değişken kalınlıklı FD kirişlerin titreşim analizini yapmışlardır.

$\mathrm{Bu}$ çalışmada kullanılan TFY, daha önceki çalışmalarda birçok mühendislik mekaniği probleminin çözümünde etkin bir şekilde uygulanmıştır [18-28].

Yapılan literatür taramasında, FD kirişlerin serbest titreşimine ait pek çok çalıșma bulunmuştur. Ancak, bu kirişlerin dinamik yükler altındaki sönümlü ve sönümsüz zorlanmış titreşim analizi ile ilgili çalışmaların kısıtlı olduğu anlaşılmaktadır. Yazarların yapmış olduğu araştırmalarda, kalınlık boyunca FD malzemeli, Euler-Bernoulli ve Timoshenko kirișlerinin sönümlü ve sönümsüz zorlanmış titreşim davranışını TFY ile inceleyen herhangi bir çalışmayla karşılaşılmamıştır. Bu tür kirişlerin dinamik yükler etkisindeki davranışları, ilk defa bu çalışmada TFY ile analiz edilmiştir. Olayı idare eden kanonik denklemler, minimum toplam enerji prensibi ile elde edilmiştir.

$\mathrm{Bu}$ çalışmanın temel amacı, kalınlık boyunca FD malzemeli kirişlerin dinamik yükler altında beklenen davranışını belirlemenin yanı sıra, bu metodun etkin ve kolayca uygulanabilirliğini de göstermektir.

$\mathrm{Bu}$ çalışmada, Fortran dilinde bir bilgisayar programı yazılarak, Euler-Bernoulli ve Timoshenko kirişlerinin zorlanmış titreşim analizleri yapılmıștır.

\section{MATERYAL VE METOT}

Şekil 1'de görülen FD malzemeli kirişin malzeme değişim fonksiyonu Eşitlik 1'de verilmektedir.

$P(z)=\left(P_{a}-P_{s}\right)\left(\frac{z}{h}+\frac{1}{2}\right)^{n_{z}}+P_{s}$

Burada $n_{z}$ malzeme değişim katsayısı, $P_{a}$ ve $P_{s}$ ise, sırasıyla alüminyum ve seramik bileşenlerine ait malzeme özellikleridir. Buna göre, elastisite modülü, $E(z)$ ve kütlesel yoğunluk, $\rho(z)$ kiriş kalınlığı boyunca üstel olarak değişmektedir. Eksenel ve düşey yer değiştirmeler $U_{x}$ ve $U_{z}$, şekil değiştirmeler ise $\varepsilon_{\mathrm{x}}$ ve $\gamma_{\mathrm{xz}}$ olup, bu büyüklükler.

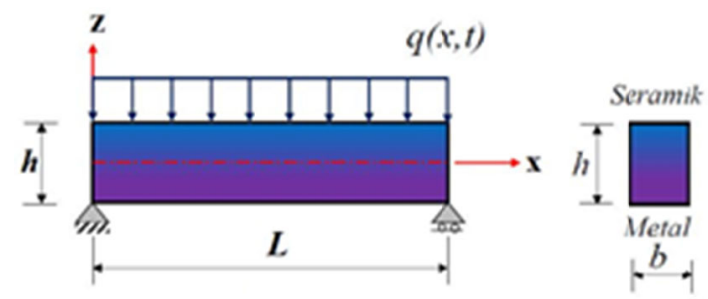

Şekil 1. FD kiriş ve malzeme değişimi

Timoshenko kiriş teorisi için sırasıyla Eşitlik 2-4'de verilmektedir.

$\mathrm{U}_{\mathrm{x}}=\mathrm{u}(\mathrm{x}, \mathrm{t})+\mathrm{z} \theta(\mathrm{x}, \mathrm{t}) ; \mathrm{U}_{\mathrm{z}}=\mathrm{w}(\mathrm{x}, \mathrm{t})$

$\varepsilon_{\mathrm{x}}=\frac{\partial \mathrm{U}_{\mathrm{x}}}{\partial \mathrm{x}}=\mathrm{u}^{\prime}+\mathrm{z} \theta^{\prime}$

$\gamma_{\mathrm{xz}}=\theta+\mathrm{w}^{\prime}$

İç kuvvetler ve gerilmeler arasındaki ilişkiler Eşitlik 5-7'de verilmektedir.

$\mathrm{N}_{\mathrm{x}}=\mathrm{b} \int_{-\mathrm{h} / 2}^{+\mathrm{h} / 2} \sigma_{\mathrm{x}} \mathrm{dz}=\mathrm{b} \int_{-\mathrm{h} / 2}^{+\mathrm{h} / 2} \mathrm{E}(\mathrm{z})\left(\varepsilon_{\mathrm{x}}\right) \mathrm{dz}$ 
$\mathrm{M}_{\mathrm{x}}=\mathrm{b} \int_{-\mathrm{h} / 2}^{+\mathrm{h} / 2} \sigma_{\mathrm{x}} \mathrm{zdz}=\mathrm{b} \int_{-\mathrm{h} / 2}^{+\mathrm{h} / 2} \mathrm{E}(\mathrm{z})\left(\varepsilon_{\mathrm{x}}\right) \mathrm{zdz}$

$\mathrm{Q}_{\mathrm{z}}=\mathrm{b} \int_{-\mathrm{h} / 2}^{+\mathrm{h} / 2} \mathrm{k}_{\mathrm{s}} \tau_{\mathrm{xz}} \mathrm{dz}=\mathrm{b} \int_{-\mathrm{h} / 2}^{+\mathrm{h} / 2} \mathrm{k}_{\mathrm{s}} \frac{\mathrm{E}(\mathrm{z})}{2(1+\mathrm{v})} \gamma_{\mathrm{xz}} \mathrm{dz}$

Burada $\mathrm{k}_{\mathrm{s}}$, kayma düzeltme faktörü ve $\mathrm{v}$ ise Poisson oranı olup, bu çalışmada sabit olarak alınmaktadır. Kesit tesirlerinin açı ifadesi ise Eşitlik 8-10'da verilmiştir.

$\mathrm{N}_{\mathrm{x}}=\mathrm{b}\left(\mathrm{A}_{11} \mathrm{u}^{\prime}+\mathrm{A}_{12} \theta^{\prime}\right)$

$\mathrm{Q}_{\mathrm{z}}=\mathrm{b} \mathrm{A} \mathrm{A}_{33}\left(\theta+\mathrm{w}^{\prime}\right)$

$\mathrm{M}_{\mathrm{x}}=\mathrm{b}\left(\mathrm{A}_{12} \mathrm{u}^{\prime}+\mathrm{A}_{22} \theta^{\prime}\right)$

$\mathrm{Bu}$ denklemlerde görülen $\mathrm{A}_{11}, \mathrm{~A}_{12}, \mathrm{~A}_{22}$ ve $\mathrm{A}_{33}$ kesit rijitlik sabitlerini ifade etmekte olup, Eşitlik 11-14'de verilen integrallerden hesaplanmaktadır.

$\mathrm{A}_{11}=\int_{-\mathrm{h} / 2}^{+\mathrm{h} / 2} \mathrm{E}(\mathrm{z}) \mathrm{dz}$

$\mathrm{A}_{12}=\int_{-\mathrm{h} / 2}^{+\mathrm{h} / 2} \mathrm{E}(\mathrm{z}) \mathrm{z} \mathrm{dz}$

$\mathrm{A}_{22}=\int_{-\mathrm{h} / 2}^{+\mathrm{h} / 2} \mathrm{E}(\mathrm{z}) \mathrm{z}^{2} \mathrm{dz}$

$\mathrm{A}_{33}=\mathrm{k}_{\mathrm{s}} \int_{-\mathrm{h} / 2}^{+\mathrm{h} / 2} \frac{\mathrm{E}(\mathrm{z})}{2(1+\mathrm{v})} \mathrm{dz}$

FD çubuklar için kinetik enerji ve toplam potansiyel enerji ifadeleri, Eşitlik 15 ve 16 integralleri ile tanımlanmaktadır.

$\Pi_{\mathrm{t}}=\int_{0}^{1} \int_{\mathrm{A}} \frac{1}{2}\left(\sigma_{\mathrm{x}} \varepsilon_{\mathrm{x}}+\tau_{\mathrm{xz}} \gamma_{\mathrm{xz}}\right)-\left(\mathrm{p}_{\mathrm{x}} \mathrm{u}+\mathrm{p}_{\mathrm{z}} \mathrm{w}\right) \mathrm{dAdx}$

$\mathrm{T}=\frac{1}{2} \int_{0}^{1} \int_{\mathrm{A}} \rho(\mathrm{z})\left(\dot{\mathrm{U}}_{\mathrm{x}}^{2}+\dot{\mathrm{U}}_{\mathrm{z}}^{2}\right) \mathrm{dAdx}$

Burada $\dot{U}_{x}$ ve $\dot{U}_{z}$ ise sırasıyla, kiriş üzerindeki bir noktanın hızının $\mathrm{x}$ (yatay) ve $\mathrm{z}$ (düşey) bileşenlerini ifade etmektedir.

Kinetik enerjiden potansiyel enerji çıkartılarak sistemin Langrangian'1 elde edilmekte ve Eşitlik 17'de verilmektedir.

$\mathrm{L}=\mathrm{T}-\Pi_{\mathrm{t}}$
Hamilton Prensibi ise, Lagrangian'ın zamana göre integralinin varyasyonunu sifir yapan varsayımdır.

$\delta \int_{\mathrm{t} 0}^{\mathrm{t} 1} \mathrm{~L} \mathrm{dt}=0$

Gerekli büyüklüklerin impulsif bileşenleri ve türevleri teşkil edilerek, kalınlık boyunca FD malzemeli kirişlerin zorlanmış titreşim davranışını idare eden kısmi diferansiyel denklemler elde edilmiş ve Eşitlik 19-24'de verilmiştir.

$\frac{\partial \mathrm{u}}{\partial \mathrm{x}}=\frac{\mathrm{A}_{12} \mathrm{M}_{\mathrm{x}}-\mathrm{A}_{22} \mathrm{~N}_{\mathrm{x}}}{\mathrm{b}\left(\mathrm{A}_{12}{ }^{2}-\mathrm{A}_{11} \mathrm{~A}_{22}\right)}$

$\frac{\partial \mathrm{w}}{\partial \mathrm{x}}=\frac{\mathrm{Q}_{\mathrm{z}}}{\mathrm{bk}_{\mathrm{s}} \mathrm{A}_{33}}-\theta$

$\frac{\partial \theta}{\partial x}=\frac{-\mathrm{A}_{11} \mathrm{M}_{\mathrm{x}}+\mathrm{A}_{12} \mathrm{~N}_{\mathrm{x}}}{\mathrm{b}\left(\mathrm{A}_{12}{ }^{2}-\mathrm{A}_{11} \mathrm{~A}_{22}\right)}$

$\frac{\partial \mathrm{N}_{\mathrm{x}}}{\partial \mathrm{x}}=-\mathrm{p}_{\mathrm{x}}+\mathrm{I}_{0} \frac{\partial^{2} \mathrm{u}}{\partial \mathrm{t}^{2}}+\mathrm{I}_{1} \frac{\partial^{2} \theta}{\partial \mathrm{t}^{2}}$

$\frac{\partial \mathrm{Q}_{\mathrm{z}}}{\partial \mathrm{x}}=-\mathrm{p}_{\mathrm{z}}+\mathrm{I}_{0} \frac{\partial^{2} \mathrm{w}}{\partial \mathrm{t}^{2}}$

$\frac{\partial \mathrm{M}_{\mathrm{x}}}{\partial \mathrm{x}}=\mathrm{Q}_{\mathrm{z}}+\mathrm{I}_{1} \frac{\partial^{2} \mathrm{u}}{\partial \mathrm{t}^{2}}+\mathrm{I}_{2} \frac{\partial^{2} \theta}{\partial \mathrm{t}^{2}}$

Burada $\mathrm{I}_{0}, \mathrm{I}_{1}$ ve $\mathrm{I}_{2}$, kütlesel atalet momentlerini temsil etmektedir. Euler-Bernoulli kiriş teorisi kullanıldı̆̆ında, Eşitlik 20'deki $\frac{\mathrm{Q}_{\mathrm{z}}}{\mathrm{b} \mathrm{k}_{\mathrm{s}} \mathrm{A}_{33}}$ terimi ihmal edilecektir. Sönümlü zorlanmış titreşim durumunda Kelvin tipi viskoz sönüm modeli, $\mathrm{E}_{\mathrm{v}}=\mathrm{E}(1+\mathrm{gs}$ ) kullanılmıştır (bkz.[29-31]). Burada $g$, sönüm oranıdır. Eşitlik 19-24'de sıfır başlangıç şartları altında Laplace dönüşümü alındığında, sistem hareket denklemleri dönüşmüş uzayda adi diferansiyel denklem takımı haline gelmektedir. Böylece, FD malzemeli kirişlerin zorlanmış titreşim davranışını idare eden adi diferansiyel denklem takımı, kanonik formda elde edilmektedir.

Eşitlik 25-30'da $\left(^{-}\right)$ile gösterilen terimler, ilgili büyüklüklerin Laplace dönüşümünü belirtmektedir. s, Laplace parametresi olup, 
kompleks bir sayıdır. Eşitlik 25-30 matris formunda aşağıdaki gibi tanımlanabilir.

$\frac{\mathrm{d} \overline{\mathrm{u}}}{\mathrm{dx}}=\frac{\mathrm{A}_{12} \overline{\mathrm{M}}_{\mathrm{x}}-\mathrm{A}_{22} \overline{\mathrm{N}}_{\mathrm{x}}}{\mathrm{b}\left(\mathrm{A}_{12}{ }^{2}-\mathrm{A}_{11} \mathrm{~A}_{22}\right)}$

$\frac{\mathrm{d} \overline{\mathrm{w}}}{\mathrm{dx}}=\frac{\overline{\mathrm{Q}}_{\mathrm{z}}}{\mathrm{bk}_{\mathrm{s}} \mathrm{A}_{33}}-\bar{\theta}$

$\frac{\mathrm{d} \bar{\theta}}{\mathrm{dx}}=\frac{-\mathrm{A}_{11} \overline{\mathrm{M}}_{\mathrm{x}}+\mathrm{A}_{12} \overline{\mathrm{N}}_{\mathrm{x}}}{\mathrm{b}\left(\mathrm{A}_{12}{ }^{2}-\mathrm{A}_{11} \mathrm{~A}_{22}\right)}$

$\frac{\mathrm{d} \overline{\mathrm{N}}_{\mathrm{x}}}{\mathrm{dx}}=-\overline{\mathrm{p}}_{\mathrm{x}}+\mathrm{I}_{0} \mathrm{~s}^{2} \overline{\mathrm{u}}+\mathrm{I}_{1} \mathrm{~s}^{2} \bar{\theta}$

$\frac{\mathrm{d} \overline{\mathrm{Q}}_{\mathrm{z}}}{\mathrm{dx}}=-\overline{\mathrm{p}}_{\mathrm{z}}+\mathrm{I}_{0} \mathrm{~s}^{2} \overline{\mathrm{w}}$

$\frac{\mathrm{d} \overline{\mathrm{M}}_{\mathrm{x}}}{\mathrm{dx}}=\overline{\mathrm{Q}}_{\mathrm{z}}+\mathrm{I}_{1} \mathrm{~s}^{2} \overline{\mathrm{u}}+\mathrm{I}_{2} \mathrm{~s}^{2} \bar{\theta}$

Burada $x$, bağımsız değişkendir. Eşitlik 31, TFY ile çözülmektedir. $\mathrm{Bu}$ yöntem, iki noktalı sınır değer problemini başlangıç değer problemine indirgemektedir. Bu denklemin genel çözümü ise Eşitlik 32'deki gibidir.

$\frac{\mathrm{d}\{\overline{\mathrm{Y}}(\mathrm{x}, \mathrm{s})\}}{\mathrm{dx}}=[\overline{\mathrm{A}}(\mathrm{x}, \mathrm{s})]\{\overline{\mathrm{Y}}(\mathrm{x}, \mathrm{s})\}+\{\overline{\mathrm{F}}(\mathrm{x}, \mathrm{s})\}$

$\{\mathrm{Y}(\mathrm{x}, \mathrm{s})\}=\sum_{\mathrm{m}=1}^{\mathrm{n}} \mathrm{C}_{\mathrm{m}}\left[\overline{\mathrm{U}}^{(\mathrm{m})}(\mathrm{x}, \mathrm{s})\right]+\{\overline{\mathrm{V}}(\mathrm{x}, \mathrm{s})\}$

Burada $\left[\mathrm{U}^{(\mathrm{m})}(\mathrm{x}, \mathrm{s})\right]$ homojen çözüm olup, m’inci bileşenine 1, diğerlerine sıfir değeri verilerek elde edilir. $\{\mathrm{V}(\mathrm{x}, \mathrm{s})\}$ ise özel çözüm olup, başlangıç şartları sıfır alınarak elde edilmektedir. İntegrasyon sabitleri $\left(\mathrm{C}_{\mathrm{m}}\right)$ ise, problemin sınır şartlarından elde edilmektedir (bkz. [18-28]).

\section{SAYISAL UYGULAMALAR}

$\mathrm{Bu}$ çalışmada, kalınlık boyunca FD malzemeli kirişlerin farklı dinamik yükler altında elastik ve viskoelastik analizlerini yapan Fortran dilinde bir bilgisayar programı hazırlanmıştır. Programda, TFY'ye dayalı başlangıç değer probleminin Laplace uzayında çözümü RK5 algoritması ile yapılmıştır. Analizlerden elde edilen sonuçların zaman uzayına dönüşümü için Durbin [32] ve Temel [33] tarafından verilen, modifiye edilmiş ters Laplace metodu uygulanmıştır.

Sayısal uygulamalarda FD malzemeler için Çizelge 1'de verilen malzeme özellikleri kullanılmıştır.

Çizelge 1. Malzemelerin mekanik özellikleri

\begin{tabular}{|l|c|c|}
\hline Malzeme & $E(\mathrm{Gpa})$ & $\rho\left(\mathrm{kg} / \mathrm{m}^{3}\right)$ \\
\hline Alüminyum $\left(P_{a}\right)$ & 70 & 2702 \\
\hline Seramik $\left(P_{S}\right)$ & 380 & 3960 \\
\hline
\end{tabular}

Ele alınan tüm FD kirişlere ait geometrik özellikler şöyledir: kesit kare $(b=h)$ olup, Timoshenko kirişi için kayma düzeltme faktörü 5/16 olarak alınmıştır.

\section{Uygulama 1}

İlk olarak önerilen metotla ankastre-ankastre sınır şartlarına sahip adım tipi yük etkisindeki homojen izotrop Timoshenko kirişin (Şekil 2) elastik ve viskoelastik $(g=0,0001)$ analizleri yapılmıştır. Aynı durumlar göz önünde bulundurularak, ANSYS sonlu eleman paket programı ile de çözümler elde edilmiştir.
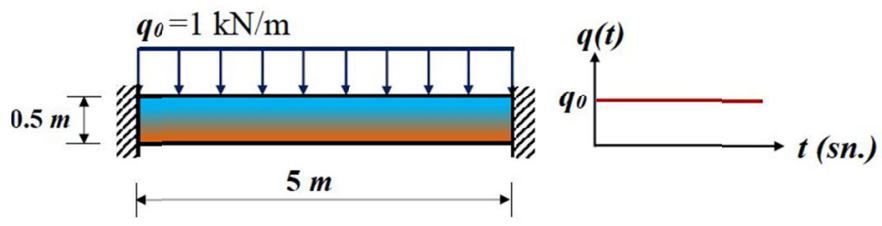

Şekil 2. FD kiriş ve dinamik yük fonksiyonu

TFY ve sonlu elemanlar [34] ile elde edilen sonuçlar birlikte Şekil 3'de gösterilmiştir. Bu grafik incelendiğinde, TFY ile Laplace uzayında az sayıda zaman adımı ve kaba zaman artımı (64 adım, $d t=0,0005 \mathrm{sn}$ ) kullanılarak elde edilen deplasman değerlerinin, sonlu elemanlar ile çok 
sayıda zaman adımı ve çok sık zaman artımı (512 adım, $d t=0,000062 \mathrm{sn})$ alınarak elde edilen sonuçlarının üst üste düştüğü görülmektedir (Şekil 3).

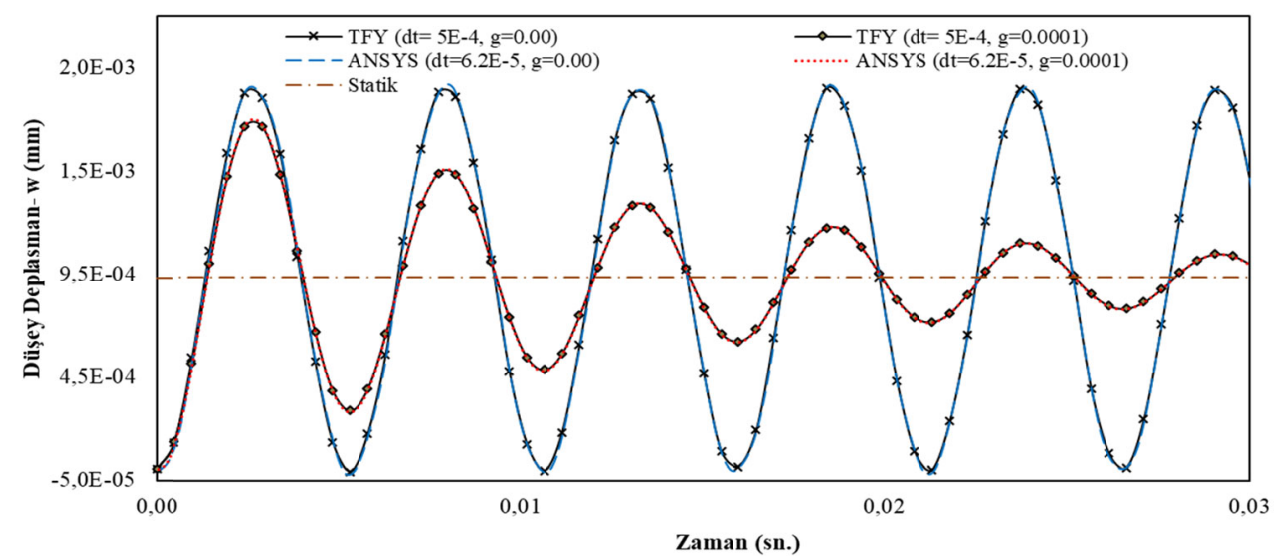

Şekil 3. Adım tipi yükleme için homojen izotrop $\left(n_{z}=0\right)$ kirişin ortasındaki düşey deplasman

Aynı geometri ve yüklemeler ve $\mathrm{n}_{\mathrm{z}}=1$ için FD edilen sonuçlar Şekil 4'de karşılaştırılmış ve uyum kirişin dinamik davranışı araştırılmıştır. Elde içerisinde olduğu görülmüştür.

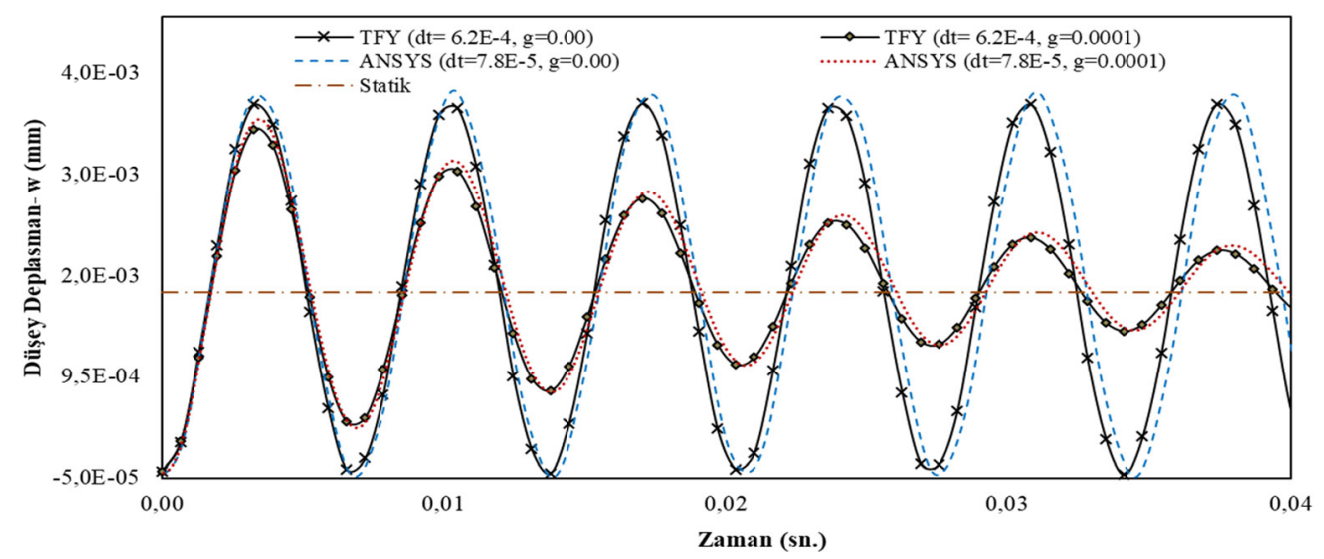

Şekil 4. Adım tipi yükleme ve $\mathrm{n}_{\mathrm{z}}=1$ için FD kirişin ortasındaki düşey deplasman

ANSYS ile modellemede BEAM188 kiriş elemanı kullanılmıştır. Bu eleman kalın kirişlerin analizi için uygun bir eleman olup, Timoshenko kiriş teorisine dayanmaktadır. $\mathrm{Bu}$ elemanın her düğümünde $\mathrm{x}, \mathrm{y}$ ve $\mathrm{z}$ doğrultularında ötelenmeler ve bu eksenler etrafinda dönmeler olmak üzere toplam 6 adet serbestlik bulunmaktadır.

ANSYS modelinde FD malzemeyi tanımlayabilmek için kiriş, uzunluğu boyunca 50 elemana ve kalınlığı boyunca ise 18 katmana bölünmüştür. Her bir katman için Eşitlik 1 ile verilen elastisite modülü ve yoğunluk değerleri ayrı ayrı tanımlanmıştır.

\section{Uygulama 2}

Bu uygulamada, Euler-Bernoulli ve Timoshenko kirişlerinin (Şekil 5), adım tipi dinamik yük etkisinde farklı FD malzeme değişim katsayıları $\left(n_{z}=0,1,2,5\right)$ ve $L / h=100$ oranı için elastik davranışı araştırılmıştır. $n_{z}=0$, izotropik homojen malzeme durumunu göstermektedir. 


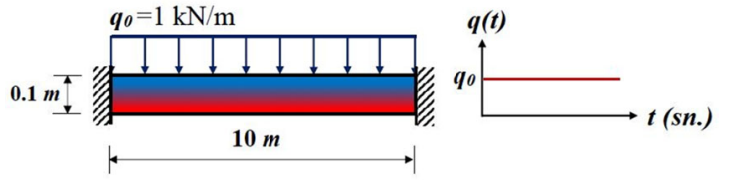

Verilen kirişlerin ortasındaki düşey deplasman, Euler-Bernoulli teorisi (EBT) için Şekil 6'da, Timoshenko teorisi (TBT) için ise Şekil 7'de verilmiştir.

Şekil 5. FD kiriş ve dinamik yük fonksiyonu

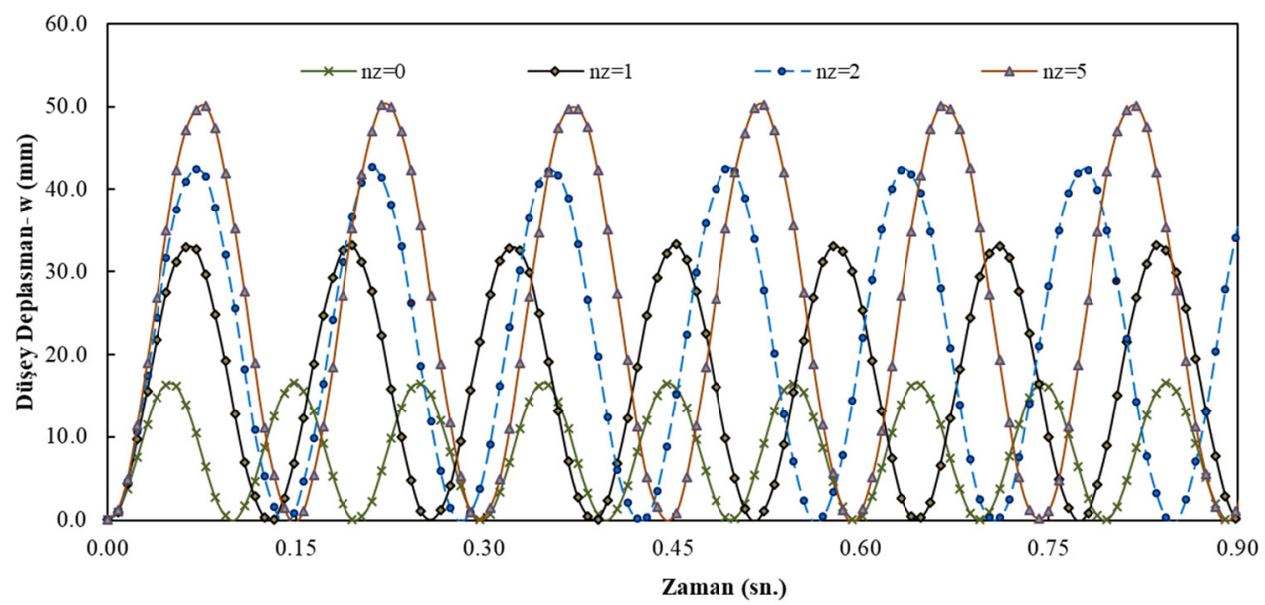

Şekil 6. Adım tipi yükleme için FD Euler-Bernoulli kirişinin ortasındaki düşey deplasman

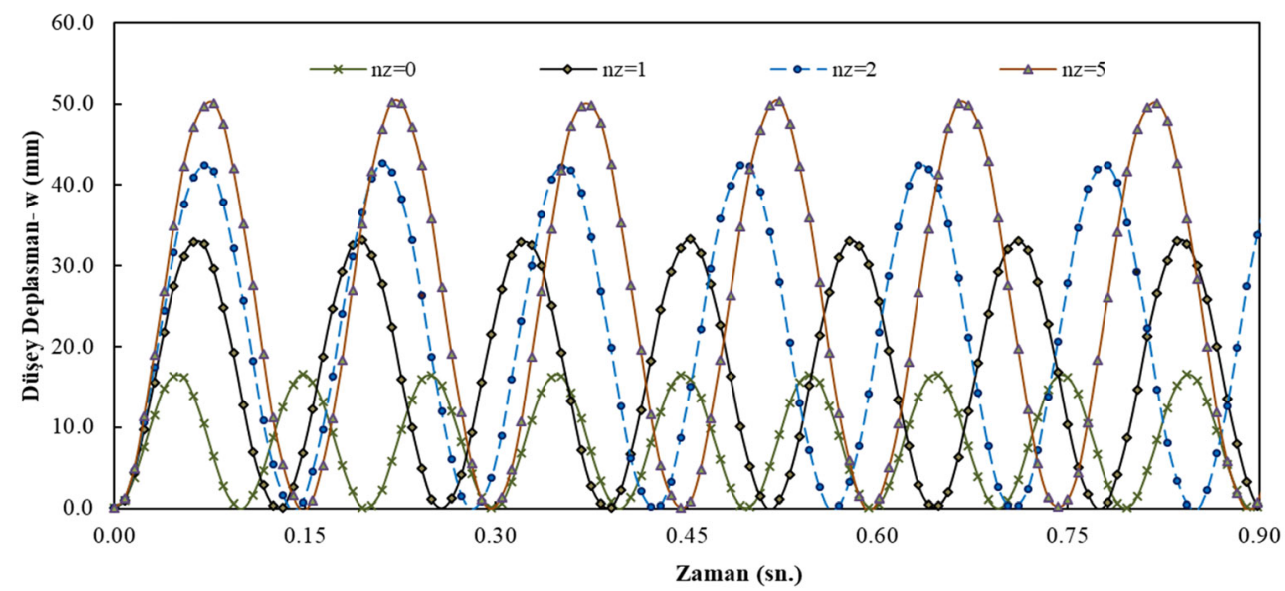

Şekil 7. Adım tipi yükleme için FD Timoshenko kirişinin ortasındaki düşey deplasman

Grafikler incelendiğinde, her iki kiriş teorisi için malzeme değişim katsayısı arttıkça düşey deplasmanların da arttığı görülmektedir. Ayrıca, $\mathrm{n}_{\mathrm{z}}=2$ durumu için her iki kiriş teorisi kullanılarak elde edilen FD kirişin ortasındaki deplasman değerleri Şekil 8'de karşılaștııılmıştır. Grafikten görüldüğü üzere, $\mathrm{L} / \mathrm{h}=100$ için sonuçların tamamen örtüştüğü anlaşılmaktadır. İnce çubuk durumunu yansıtan $\mathrm{L} / \mathrm{h}=100$ oranı için kayma şekil değiştirmesi etkisinin olmadığı ortaya çıkmaktadır.

\section{Uygulama 3}

İki ucundan ankastre mesnetli Euler-Bernoulli (EBT) ve Timoshenko (TBT) kirişlerinin (Şekil 5.) $L / h=5$ oranı ve farklı malzeme değişim katsayıları 
$\left(n_{z}=0,1,2,5\right)$ için çözümleri sırasıyla, Şekil 9-11'de gösterilmiştir. Şekiller incelendiğinde, malzeme değişim katsayısı arttıkça periyotları ve genliklerin arttığı gözlemlenmektedir.

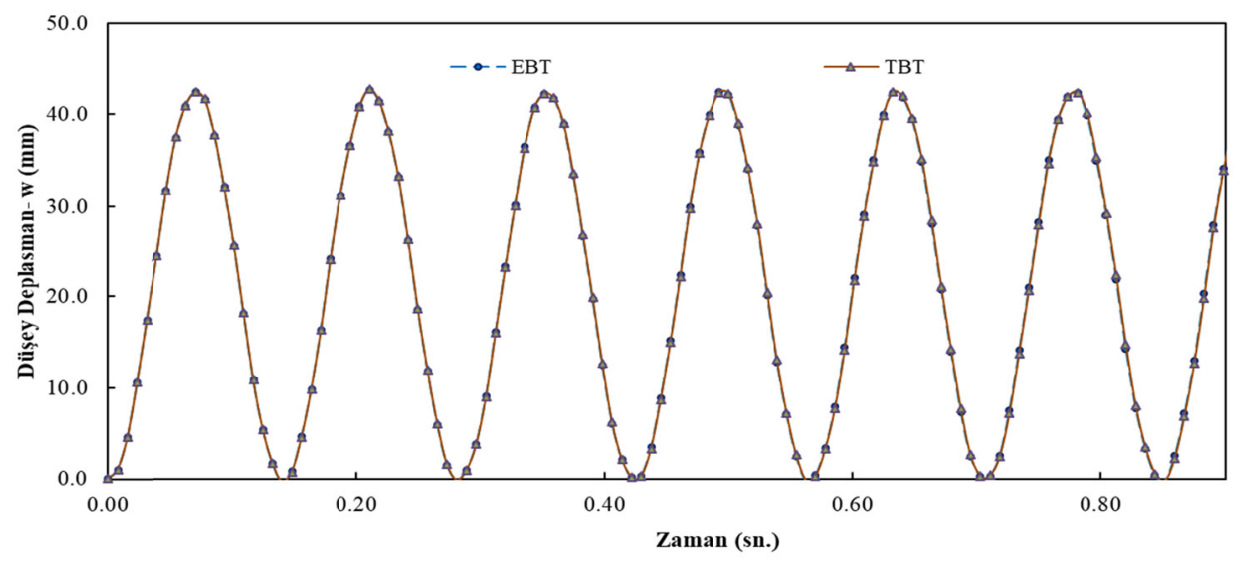

Şekil 8. Adım tipi yükleme için FD kirişin ortasındaki düşey deplasman

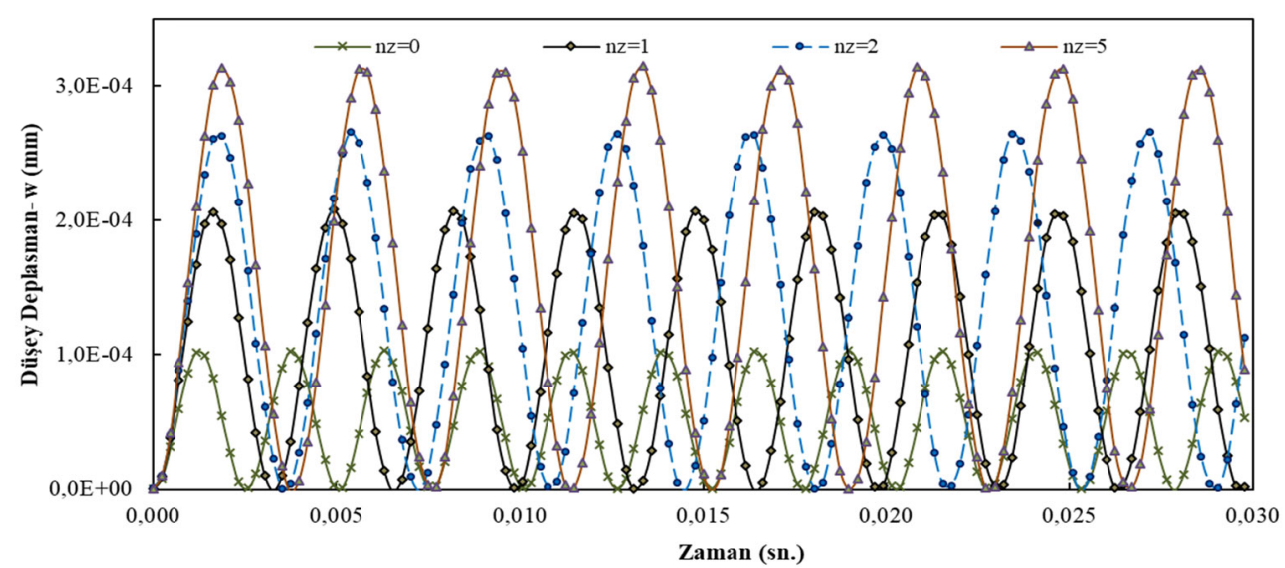

Şekil 9. Adım tipi yükleme için FD Euler-Bernoulli kirişinin ortasındaki düşey deplasman

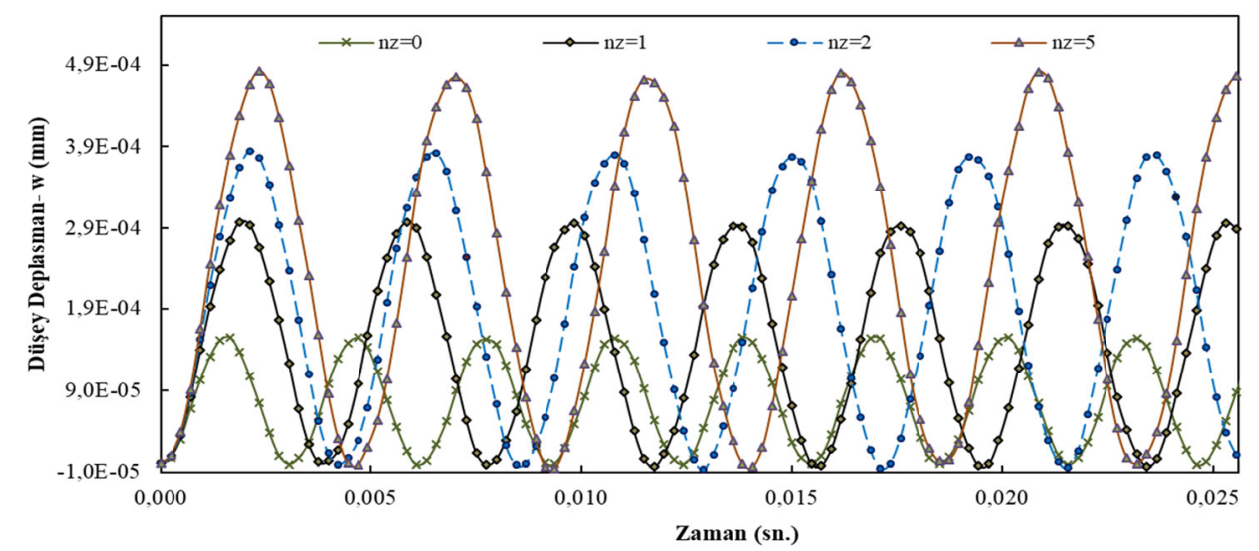

Şekil 10. Adım tipi yükleme için FD Timoshenko kirişinin ortasındaki düşey deplasman 


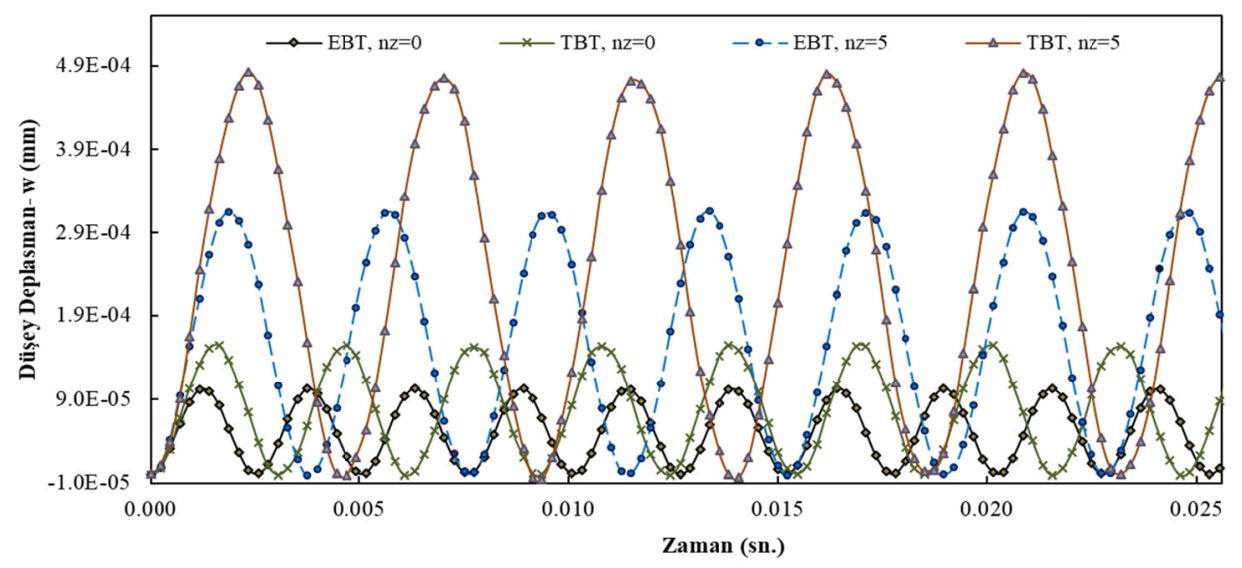

Şekil 11. Adım tipi yükleme için FD kirişin ortasındaki düşey deplasman

$\mathrm{L} / \mathrm{h}=5$ oranı için, iki ucundan ankastre mesnetli Euler-Bernoulli ve Timoshenko kirişlerinin farklı malzeme değişim katsayılarına $\left(n_{z}=0\right.$ ve 5) ait çözümler Şekil 11'de gösterilmiştir. Şekil incelendiğinde, homojen izotrop $\left(\mathrm{n}_{\mathrm{z}}=0\right)$ ve FD $\left(\mathrm{n}_{\mathrm{z}}=5\right)$ malzeme durumlarında, oran $\mathrm{L} / \mathrm{h}=5$ olduğunda, kayma şekil değiştirmesi etkisinin büyük olduğu anlaşılmaktadır.

\section{Uygulama 4}

İki ucundan sabit mesnetli FD $\left(\mathrm{n}_{\mathrm{z}}=1\right)$ Timoshenko kirişinin (Şekil 12) adım tipi dinamik yükleme altında viskoelastik zorlanmış titreşimi araştırılmıştır. Kiriş ortasındaki deplasmanın zamanla değişimi çeşitli sönüm oranları $(g=0,000$, $\mathrm{g}=0,0001$ ve $\mathrm{g}=0,0002$ ) için Şekil 13 'de çizilmiştir.

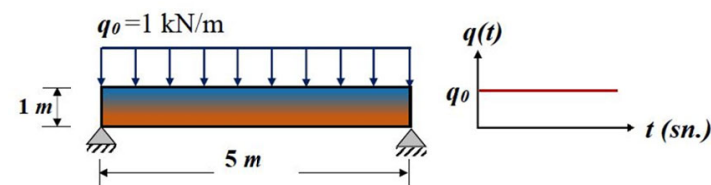

Şekil 12. FD kiriş ve dinamik yük fonksiyonu

\section{Uygulama 5}

Şekil 14'de verilen FD $\left(\mathrm{n}_{\mathrm{z}}=5\right)$ konsol kirişinin adım tipi dinamik yükleme altında elastik ve viskoelastik zorlanmış titreşimı davranışları analiz edilmiştir. Ele alınan kirişin serbest ucundaki dönmesinin zamanla değişimi, çeşitli sönüm oranları $(g=0,000, g=0,0001$ ve $g=0,0002)$ için hesaplanarak Şekil 15'de sunulmuştur.

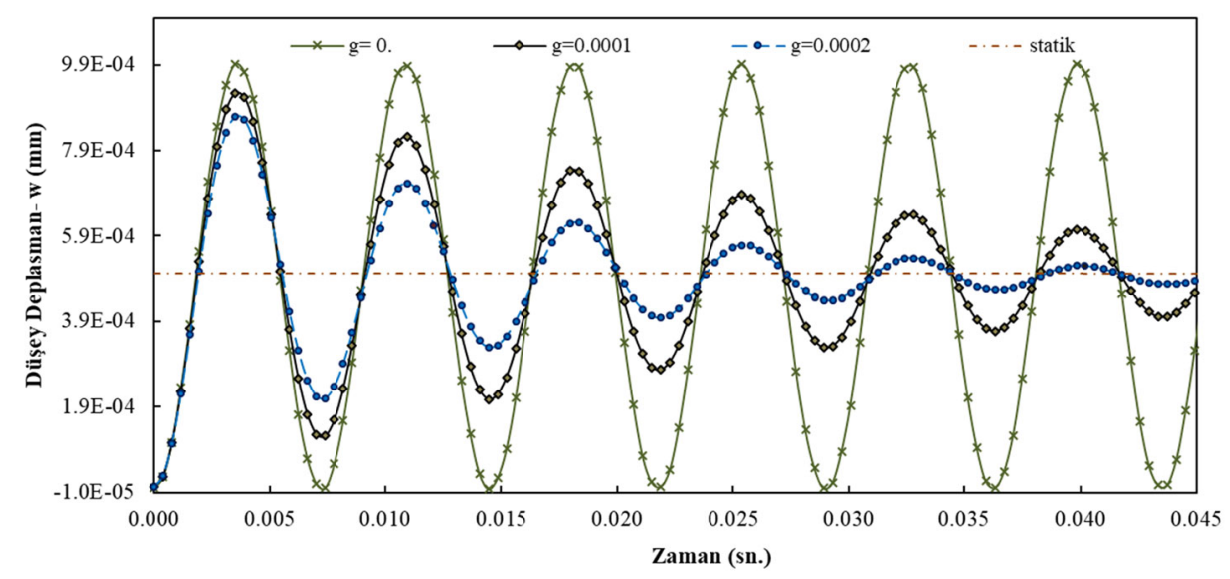

Şekil 13. Adım tipi yükleme için FD kirişin ortasındaki düşey deplasman 


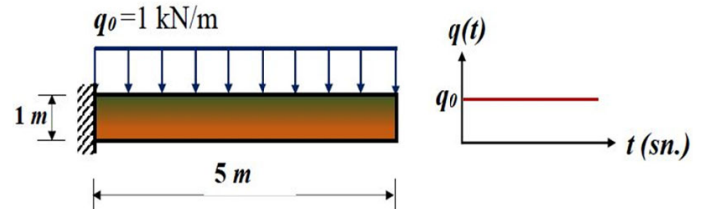

Şekil 14. FD kiriş ve dinamik yük fonksiyonu
Şekil 13 ve Şekil 15 incelendliğinde, viskoelastik malzeme durumunda deplasman ve dönme genliklerinin zamanla küçüldüğü görülmektedir. Sönüm oranı arttıkça bu titreşim genliklerinin statik değere daha çabuk yaklaştığı görülmektedir. Adım tipi dinamik yükünün Laplace dönüşümü, literatürde kapalı formda mevcuttur [35].

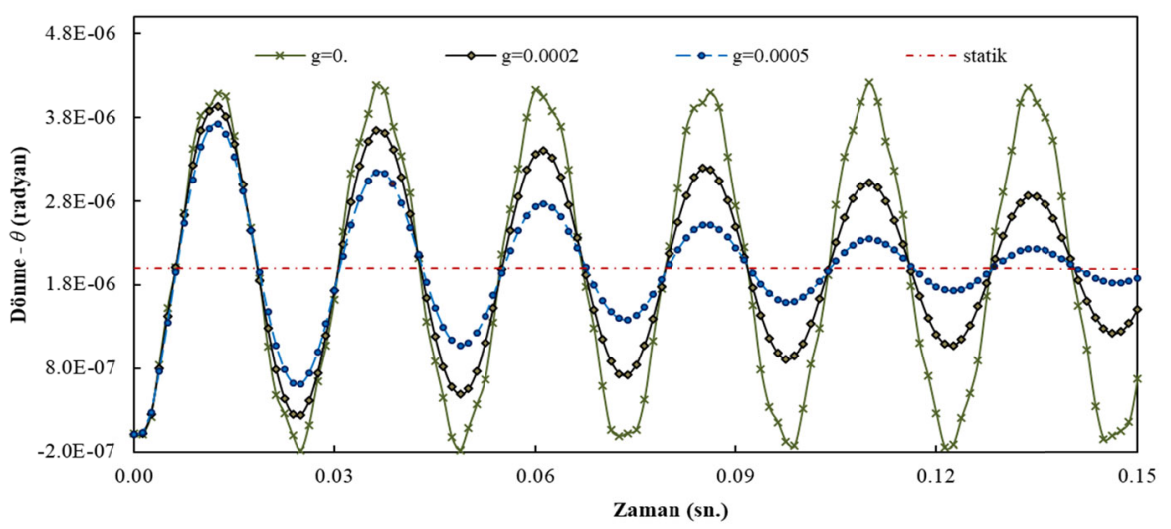

Şekil 15. Adım tipi yükleme için FD Timoshenko kirişinin konsol ucundaki dönme deplasman

\section{Uygulama 6}

Ankastre-sabit sınır koşullarına sahip olan FD kirişinin (Şekil 16) adım tipi dinamik yük etkisinde elastik davranışı ele alınmıştır.
Kirişin sabit mesnedindeki dönmenin zamanla değişimi çeşitli malzeme değişim katsayıları için elde edilmiş ve Şekil 17'de verilmiştir. $\mathrm{n}_{\mathrm{z}}$ değerleri artıkça, elastik titreşim davranışın genlikleri ve periyotları artmaktadır.

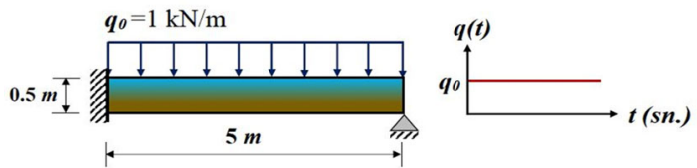

Şekil 16. FD kiriş ve dinamik yük fonksiyonu

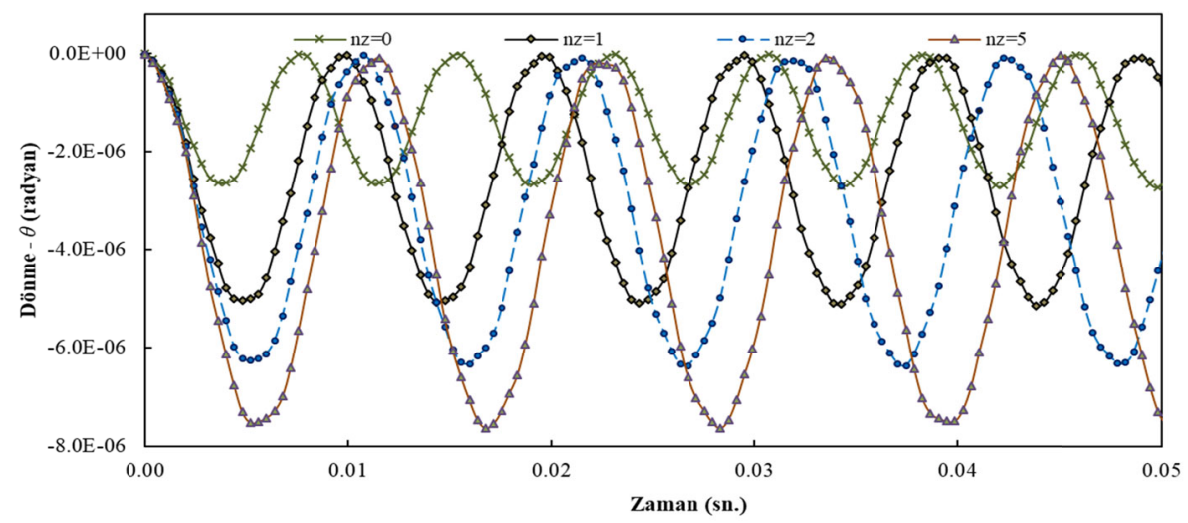

Şekil 17. Adım tipi yükleme için FD Timoshenko kirişinin sabit mesnedindeki dönme deplasman 


\section{Uygulama 7}

İki ucundan ankastre mesnetli Timoshenko kirişinin (Şekil 18) testere dişi dalga tipi yük etkisindeki zorlanmış titreşim davranışı çeşitli malzeme değişim katsayıları $\left(\mathrm{n}_{\mathrm{z}}=0,1,5\right)$ için araştırılmıştır.
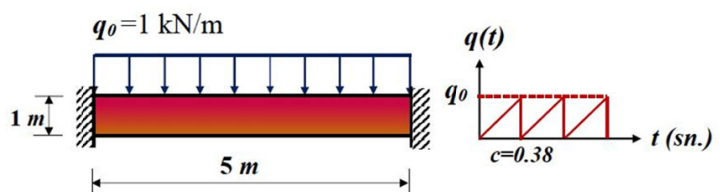

Şekil 18. FD kiriș ve dinamik yük fonksiyonu

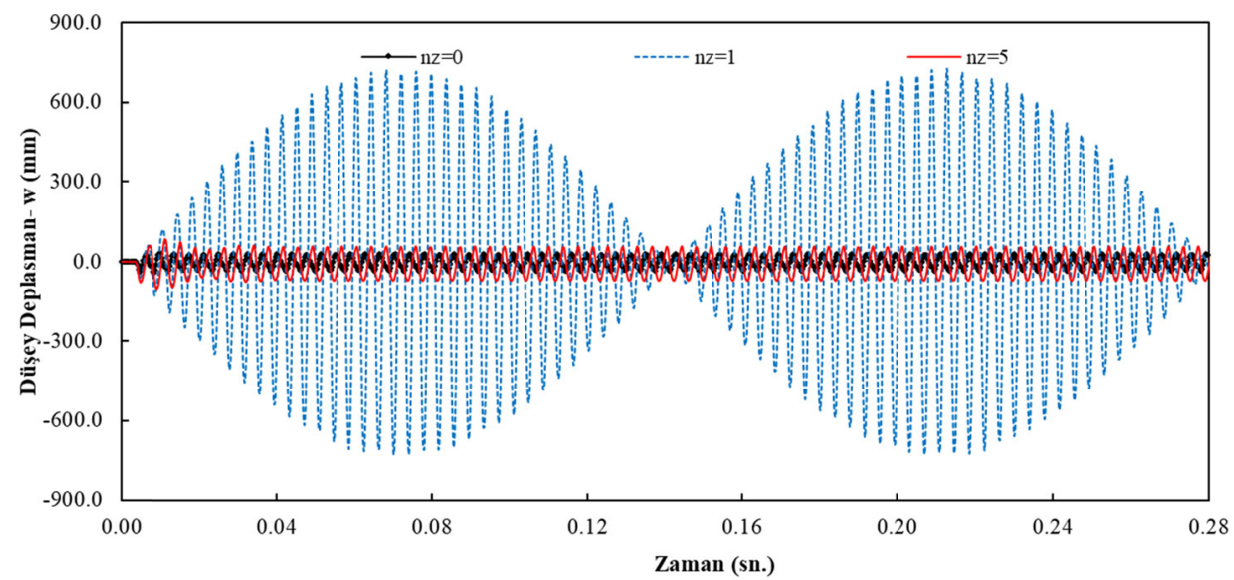

Şekil 19. Testere dişi dalga tipi için FD Timoshenko kirişinin ortasındaki düşey deplasman

\section{SONUÇLAR}

$\mathrm{Bu}$ çalışmada, kesit yüksekliği boyunca FD kirişlerin zorlanmış titreşim davranışı TFY ile Laplace uzayında sayısal olarak analiz edilmiştir. Problemin hareketini idare eden denklemler, toplam enerji prensibi yardımıyla önce zaman uzayında elde edilmiş, daha sonra Laplace uzayına taşınmıştır.

Viskoelastik malzeme sabitleri, Kelvin tipi sönüm modeli için dönüşmüş uzayda elde edilen denklemlere kolaylıkla eklenmiştir. Laplace uzayında elde edilen sonuçlar, etkin bir ters Laplace dönüşüm tekniği ile zaman uzayına taşınmıştır.
Uygulanan periyodik dalga tipi yükün frekansının $(263 \mathrm{~Hz}), \operatorname{FDM}\left(\mathrm{n}_{\mathrm{z}}=1\right)$ kirişinin doğal titreşim frekansına oldukça yakın olmasından dolayı, Şekil 19'da görüldüğü üzere, bu kirişte vuruş olay1 gözlemlenmiştir. Uygulanan bu yükün frekansının, dikkate alınan diğer iki FDM $\left(\mathrm{n}_{\mathrm{z}}=0\right.$ ve 5$)$ kirişin doğal titreşim frekanslarına uzak olduğu için kirişlerde normal elastik davranış gözlemlenmiştir. $\mathrm{Bu}$ örnekte ele alınan FD kirişlerin serbest titreşim frekansları [26] çalışmasında verilmektedir. Testere dişi dalga tipi dinamik yükünün Laplace dönüşümü ise, literatürde kapalı formda mevcuttur [35]. 
araştırılmıştır. L/h oranı $(<10)$ küçüldükçe, bu etki analizlere dahil edilmesi gerekmektedir.

Son olarak bu çalışmada önerilen metodun, ele alınan problemlerin analizi için oldukça etkin ve kolayca uygulanabilir olduğu anlaşılmıştır.

\section{KAYNAKLAR}

1. Qian, L.F., Ching, K.H., 2004. Static and Dynamic Analysis of 2-D Functionally Graded Elasticity by Using Meshless Local PetrovGalerkin Method. Journal of the Chinese Institute of Engineers, 27(4), 491-503.

2. Aydoğdu, M., Taşkın, V., 2007. Free Vibration Analysis of Functionally Graded Beams with Simply Supported Edges. Materials \& Design, 28(5), 1651-1656.

3. Li, X.F., 2008. A Unified Approach for Analyzing Static and Dynamic Behaviors of Functionally Graded Timoshenko and Eulerbernoulli Beams. Journal of Sound and Vibrations, 318, 1210-1229.

4. Sina, S.A., Navazi, H.M., Haddadpour, H., 2009. An Analytical Method for Free Vibration Analysis of Functionally Graded Beams. Materials and Design, 30, 741-747.

5. Civalek, Ö., Kiracioglu, O., 2010. Free Vibration Analysis of Timoshenko Beams by DSC Method. Int. J. Numer. Meth. Biomed. Engng., 26, 1890-1898.

6. Alshorbagy, A.E., Eltaher, M.A., Mahmoud, F.F., 2011. Free Vibration Characteristics of a Functionally Graded Beam by Finite Element Method. Applied Mathematical Modelling, 35, 412-425.

7. Atmane, H.A., Tounsi, A., Meftah, S.A., Belhadj, H.A., 2011. Free Vibration Behavior of Exponential Functionally Graded Beams with Varying Cross-section. Journal of Vibration and Control, 17(2), 311-318.

8. Anandrao, K.S., Gupta, R.K., Ramachandran, P., Rao, G.V., 2012. Free Vibration Analysis of Functionally Graded Beams. Defence Science Journal, 62(3), 139-146.

9. Pradhan, K.K., Chakraverty, S., 2013. Free Vibration of Euler and Timoshenko
Functionally Graded Beams by Rayleigh-ritz Method. Composites: Part B, 51, 175-184.

10. Demir, C., Öz, F.E., 2013. Free Vibration Analysis of a Functionally Graded Viscoelastic Supported Beam. Journal of Vibration and Control. DOI: 10.1177/1077546313479634.

11. Su, H., Banerjee, J.R., 2015. Development of Dynamic Stiffness Method for Free Vibration of Functionally Graded Timoshenko Beams. Computers and Structures 147, 107-116.

12. Jing, L.L., Ming, P.J., Zhang, W.P., Fu, L.R., Cao, Y.P., 2016. Static and Free Vibration Analysis of Functionally Graded Beams by Combination Timoshenko Theory and Finite Volume Method. Composite Structures, 138, 192-213.

13. Avcar, M., Alwan, H.H.A., 2017. Free Vibration of Functionally Graded Rayleigh Beam. International Journal of Engineering \& Applied Sciences (IJEAS), 9(2), 127-137.

14. Lee, J.W., Lee, J.Y., 2017. Free Vibration Analysis of Functionally Graded BernoulliEuler Beams Using an Exact Transfer Matrix Expression. International Journal of Mechanical Sciences, 122, 1-17.

15. Turan, M., Kahya, V., 2018. Fonksiyonel Derecelendirilmiş Kirişlerin Serbest Titreşim Analizi. Karadeniz Fen Bilimleri Dergisi, 8(2), 119-130, DOI: $10.31466 / \mathrm{kfbd} .453833$.

16. Akbaş, Ş.D., $2018 . \quad$ Fonksiyonel Derecelendirilmiş Ortotropik Bir Kirişin Statik ve Titreşim Davranışlarının İncelenmesi, BAUN Fen Bil. Enst. Dergisi, 20(1), 69-82.

17. Nam, V.H., Vinh, P.V., Nguyen Van Chinh, N.V., Thom, D.V., Hong, T.T., 2019. A New Beam Model for Simulation of the Mechanical Behaviour of Variable Thickness Functionally Graded Material Beams Based on Modified First Order Shear Deformation Theory. Materials, doi: 10.3390/ma12030404.

18. Noori, A.R., Aslan, T.A., Temel, B., 2020. Static Analysis of FG Beams via Complemantary Functions Method. European Mechanical Science, 4(1), 1-6.

19. Yildırım, S., Tütüncü, N., 2018. On the InertioElastic Instability of Variable-thickness Functionally-graded Disks. Mechanics Research Communications, 91, 1-6. 
20. Yildırım, S., Tütüncü, N., 2019. Effect of Magneto-Thermal Loads on the Rotational Instability of Heterogeneous Rotors. AIAA Journal, 57 (5) 2069-2074.

21. Yontar, O., Aydın K., Keleş, İ., 2020. Practical Jointed Approach to Thermal Performance of Functionally Graded Material Annular Fin. Journal of Thermophysics and Heat Transfer, 34(1), 144-149.

22. Çelebi, K, Yarımpabuç, D., Tütüncü, N., 2018. Free Vibration Analysis of Functionally Graded Beams Using Complementary Functions Method. Archive of Applied Mechanics, 88, 729-739.

23. Temo, A., Yarımpabuç, D., 2019. The Effect of Uniform Magnetic Field on Pressurized FG Cylindrical and Spherical Vessels. European Mechanical Science, 3(4), 133-141.

24. Çalım, F.F., 2020. Vibration Analysis of Functionally Graded Timoshenko Beams on Winkler-pasternak Elastic Foundation. Iranian Journal of Science and Technology, Transactions of Civil Engineering, 44, 901-920.

25. Çalım, F.F., 2016. Transient Analysis of Axially Functionally Graded Timoshenko Beams with Variable Cross-section. Composite Part B: Engineering, 98, 472-483.

26. Aslan, T.A., Noori, A.R., Temel B., 2019. Birinci Mertebe Kayma Deformasyon Teorisine Dayalı FD Düz Eksenli Kirişlerin Serbest Titreşim Analizi. Çukurova Üniversitesi Mühendislik Mimarlık Fakültesi Dergisi, 34(4), 21-28.

27. Aslan, T.A., Noori, A.R., Temel, B., 2019. Çift Yönlü Fonksiyonel Derecelenmiş Malzemeli Tımoshenko Kirişlerinin Serbest Titreşim Analizi. Ömer Halisdemir Üniversitesi Mühendislik Bilimleri Dergisi, 8(3), 30-36.

28. Temel B., Noori, A.R., 2020. A Unified Solution for the Vibration Analysis of Twodirectional Functionally Graded Axisymmetric Mindlin-Reissner Plates with Variable Thickness. International Journal of Mechanical Sciences, 174, 1-20.

29. Boley, B.A., Weiner, J.H., 1960. Theory of Thermal Stresses, John Wiley and Sons, New York.
30. Aslan, T.A., Noori, A.R., Temel, B., 2018 Dikdörtgen Kesitli Viskoelastik Sikloid Çubukların Zorlanmış Titreşimi, Çukurova Üniversitesi Mühendislik Mimarlık Fakültesi Dergisi, 33(1), 151-162.

31. Temel, B., Çalım, F.F., Tütüncü, N., 2004. Quasi-Static and Dynamic Response of Viscoelastic Helical Rods. Journal of Sound and Vibration, 271, 921-935.

32. Durbin, F., 1974. Numerical Inversion of Laplace Transforms: an Efficient Improvement to Dubner and Abate's Method. Computer Journal, 17, 371-376.

33. Temel, B., 2004. Transient Analysis of Viscoelastic Helical Rods Subject to TimeDependent Loads. International Journal of Solids and Structures, 41, 1605-1624.

34. ANSYS, 2013. Inc Release 15.0, Canonsburg, PA.

35. Spiegel, M.R., 1965. Laplace Transforms, McGraw-Hill New York. 
